\title{
Deconstruyendo el origen del daño especial en Colombia: análisis del caso "El Siglo"
}

\author{
Deconstruction Analysis of Special \\ Damages Origins in Colombia: \\ "El Siglo" Case
}

Deconstruindo a origem do dano especial na Colômbia: estudo do caso El siglo

Yuliana Ocampo Marulanda*

* http://orcid.org/0000-0001-6038-7196. Universidad de Manizales, Colombia. yocampom@umanizales.edu.co

Recibido: 29/04/2020. Envío a pares: 09/05/2020 Aprobado por pares: 29/06/2021. Aceptado: 06/07/2021

DOI: 10.5294/dika.2021.30.1.5 


\section{Resumen}

En el presente escrito se estudiará el daño especial como título de imputación en el derecho colombiano y el derecho francés, analizando las particularidades para su configuración y aplicación, tanto en la doctrina como en la jurisprudencia. Enseguida, se hará una revisión del nacimiento histórico de dicho título de imputación en el derecho colombiano, remontándose al caso "El Siglo" de 1947, fallado por el honorable Consejo de Estado, el cual se presentará y estudiará, en aras de determinar si el daño especial fue adecuadamente empleado o si lo correspondiente era la aplicación de una falla en el servicio. Finalmente, y como conclusión, se esbozará que el daño especial como título de imputación fue erróneamente empleado y, bajo dicha lógica, su verdadero origen en Colombia debe remontarse a la sentencia de 23 de mayo de 1973.

\section{Palabras clave}

Daño especial; origen; jurisprudencia; Consejo de Estado; falla del servicio; caso "El Siglo". 


\section{Abstract}

This paper analyzes special damages as an accusation method in Colombian and French law, stressing its formation and application characteristics from doctrine and case law. It makes a historical approach to special damages based on a case named "El Siglo," which took place in 1947 and was ruled by the Consejo de Estado (high constitutional court) as the principal court for public issues. This ruling is presented and discussed to determine whether special damages was appropriately employed or whether service failure was applicable. Finally, we conclude that special damages was not a valid accusation method in this case, and, therefore, its exact origin dates back to a 1973 ruling.

\section{Keywords}

Special damages; origin; case law; high constitutional court; service failure; El Siglo case. 


\section{Resumo}

No presente texto, será realizado um estudo do dano especial como título de imputação no direito colombiano e no direito francês, analisando as particularidades para sua configuração e aplicação, tanto na doutrina quanto na jurisprudência. Posteriormente, será feita uma revisão do nascimento histórico do referido título de imputação no direito colombiano, remontando ao caso "El Siglo", de 1947, definido pelo honorável Consejo de Estado, que é a mais alta corte na jurisdição pública da Colômbia. Além disso, esse caso será apresentado e estudado, com a finalidade de determinar se a aplicação do dano especial foi acertada nesse caso. Como conclusão, será determinado que o dano especial como forma de impugnação foi erroneamente utilizado e, consequentemente, que sua verdadeira origem foi na sentença de 23 de maio de 1973.

\section{Palavras-chave}

Dano especial; origem; jurisprudência; Consejo de Estado; falha no serviço; caso El Siglo. 
Sumario: Introducción. 1. La responsabilidad del Estado en Colombia. 2. El daño especial como título de imputación en la responsabilidad del Estado. 3. La doctrina, la jurisprudencia y el nacimiento del daño especial como título de imputación. 4. Los supuestos de hecho y las consideraciones del caso "El Siglo". 5. Análisis del caso "El Siglo" de 1947 y la verdadera presencia de una falla en el servicio. 6. El origen del daño especial en Colombia se remonta a 1973. Bibliografía.

\section{Introducción}

Desde la estructuración de la responsabilidad del Estado en el derecho francés ${ }^{1}$ son múltiples los avances que dicha institución jurídica ha presentado gracias a las discusiones jurisprudenciales que se han dado sobre el tema, por lo cual esta se reconoce, entonces, como una figura en constante evolución jurídica. ${ }^{2}$ Justamente, dentro de los elementos configurativos de la aludida responsabilidad, los títulos de imputación jurídica han evidenciado constantes cambios que reflejan su recorrido histórico y ampliación, razón por la cual este escrito se enfocará en uno de ellos, el daño especial.

Para efectuar un adecuado análisis de dicho título de imputación y su nacimiento en el derecho colombiano, resulta determinante comprender el origen de este en el derecho comparado, los fundamentos que dieron lugar a su consagración y la necesidad de su aplicación en Colombia.

Así las cosas, en el inicio de la responsabilidad del Estado se reconoció la posibilidad de predicar una indemnización por actuaciones $u$ omisiones de la administración, única y exclusivamente sustentadas en la culpa de esta -la falta en el servicio-, equiparando ello a los supuestos que de antología se habían erigido en el clásico derecho civil, en el cual la responsabilidad se predicaba de los particulares que incurrían en culpa o dolo, pues se predicaba un "funcionamiento indebido del servicio, no funcionamiento del servicio y funcionamiento retardado del servicio". ${ }^{3}$

Con posterioridad, dicho régimen subjetivo evolucionó para diferenciarse del plano de la culpa, al encontrar una dificultad en el establecimiento de esta o en el dolo de la administración por tratarse de un órgano o entidad abstracta, con lo cual se llegó al escenario de la falla en el servicio, estructurada como

1 El paso de la irresponsabilidad del Estado a su responsabilidad se ha reconocido en el derecho francés a partir del fallo Blanco de 1873. Al respecto véanse, entre otros: Mario Armando Echevarría Acuña, “El pensamiento liberal y su influencia en la responsabilidad del Estado", Revista Cultural Unilibre 1 (2011), p. 22; William Guillermo Jiménez, “Origen y evolución sobre las Teorías de la responsabilidad Estatal”, Revista Diálogos de saberes 38 (2013), p. 68.

2 Didier Truchet, "La evolución reciente de la responsabilidad administrativa en el derecho francés”, Juan Carlos Henao y Andrés Fernando Ospina Garzón (eds.), La responsabilidad extracontractual del Estado: ¿Qué? ¿Por qué? ¿Hasta dónde?, Bogotá, Universidad Externado de Colombia, 2015, pp. 317-332.

3 Paul Duez, La responsabilité de la puissance publique, Paris, Dalloz, 1938, p. 20. 
un título de imputación en el cual se reprocha al Estado la lesión o violación de sus obligaciones en la prestación de servicios públicos o en cualquier otra de sus actuaciones o actividades.

No obstante el referido avance jurisprudencial, la falla en el servicio se vislumbró como insuficiente para dar respuesta a distintos casos, en los que no existía un incumplimiento por parte de la administración frente a sus obligaciones, pero, se producía un daño a los ciudadanos que ante dicho escenario no encontraban posibilidad alguna de reparación. Precisamente, en dicho contexto se estructura el daño especial como título de imputación que reconoce en el caso Couitéas, ${ }^{4}$ del derecho francés, su primera aplicación.

Por supuesto, el derecho colombiano no fue indiferente ante la nueva estructuración en el derecho comparado de dicho título de imputación y llevó a cabo su aplicación en Sentencia de 1947, en el denominado caso "El Siglo", que se reconoce como la primera jurisprudencia en este país en emplear un fundamento de responsabilidad del Estado diferente al de la falla en el servicio, afirmación en la que coinciden la jurisprudencia del Consejo de Estado, la Corte Constitucional y los autores especializados en la materia.

Precisamente, es dicha circunstancia la que constituirá el objeto central de este escrito, en el que se sustentará que la doctrina y jurisprudencia colombianas han errado en reconocer dicho caso como el fundacional del título de imputación de daño especial, en la medida que allí fue incorrectamente empleado, al no satisfacer todos y cada uno de los postulados teóricos requeridos para su aplicación, de lo que resulta, entonces, que el daño especial desde sus orígenes en Colombia no ha tenido un adecuado empleo por parte de los operadores judiciales, por lo que se ha distorsionado lo contemplado en el derecho francés y se ha afectado la seguridad jurídica y la construcción dogmática que deberían prevalecer en la responsabilidad del Estado, en cualquier ordenamiento jurídico.

Así las cosas, y de manera preliminar, debe advertirse al lector que con ocasión del análisis de los postulados que a continuación se especificarán, se llegará a la conclusión de la indebida edificación del daño especial en la sentencia del Consejo de Estado de 1947, por lo que debe entenderse como el origen adecuado de este postulado en el año 1973, cuando se efectuó un uso apropiado y coherente de todos y cada uno de los elementos que permiten estructurar

$4 \quad$ En esto coinciden el derecho francés y el derecho colombiano, que reconocen el fallo Couitéas proferido por el Consejo de Estado francés el 30 de noviembre de 1923 como el primer caso en el que se estructura un fallo por un título de imputación diferente a la falla en el servicio. Al respecto véase Conseil D'état Français, "Responsabilité pour rupture de l'égalité devant les charges publiques", en https://www.conseil-etat.fr/ressources/ decisions-contentieuses/les-grandes-decisions-du-conseil-d-etat/conseil-d-etat-30-novembre-1923-couiteas, fecha de consulta: 10 de enero de 2020; Luis Guillermo Serrano Escobar y Claudia Patricia Tejada Ruiz, La responsabilidad patrimonial del Estado, Bogotá, Ediciones Doctrina y Ley, 2014. pp. 304 y 305. 
la responsabilidad del Estado en este título de imputación, transmutando de manera apropiada lo dispuesto sobre la materia en el derecho comparado.

\section{La responsabilidad del Estado en Colombia}

De manera preliminar, y antes de enfatizar en el objeto central del escrito, es preciso referir los elementos de la responsabilidad del Estado en Colombia y el papel que presenta el daño especial en dicho marco, de manera que pueda ofrecerse una mejor comprensión de los asuntos cuyo debate se pretende.

En relación con lo aludido, se debe señalar, en la actualidad, tras la expedición de la Constitución Política de Colombia de 1991, el marco jurídico de la institución por estudiar se encuentra delimitado en su artículo 90, en donde se ha reconocido la cláusula general de la responsabilidad del Estado, ${ }^{5}$ de la cual pueden deducirse los elementos ${ }^{6}$ que permitirán predicar la misma, así:

- El daño antijurídico

- La imputación.

Los elementos precedentes se han denominado el bípode de la responsabilidad del Estado, ${ }^{7}$ esto es, aquellos que constituyen la base o el sustento de la institución, de manera que su acreditación resulta indispensable para que pueda generarse un vínculo jurídico entre el victimario y la víctima que implique para el primero el deber de reparar integralmente a la segunda.

En punto del daño y las importantes exposiciones efectuadas por la doctrina, solo se hará una breve remembranza para establecer qué puede definirse como el desvalor subjetivo otorgado por un sujeto a la lesión de un interés jurídico tutelado por el ordenamiento jurídico. En procura de brindar precisión y solidez a lo reseñado, propio es aludir a algunas definiciones de este elemento, así:

En síntesis, el entender el daño en el horizonte de quebrantamiento a un interés legítimo, posibilita una visión omnicomprensiva del fenómeno dañoso más allá de las limitaciones que llevaba circunscribirlo al ámbito cerrado del derecho subjetivo y que implicaba un desconocimiento de realidades que clamaban por su resarcimiento. ${ }^{8}$

El daño es la aminoración patrimonial sufrida por la víctima. ${ }^{9}$

5 Corte Constitucional de Colombia, Sentencia C-333 de 01 de agosto de 1996, M. P. Alejandro Martínez Caballero.

6 En el presente escrito se hace una simple exposición de la responsabilidad del Estado sin que se lleve a cabo una discusión a profundidad de los demás elementos de la institución diferentes al daño especial, de allí que no se desarrollen debates profundamente interesantes en lo que corresponde a la antijuridicidad como elemento de responsabilidad.

7 Héctor Eduardo Patiño Domínguez, "El trípode o el bípode: la estructura de la responsabilidad", Henao y 136 Ospina Garzón (eds.), La responsabilidad extracontractual del Estado, op. cit., pp. 166-180.

8 Enrique Gil Botero, Temas de responsabilidad extracontractual del Estado, Bogotá, Comlibros, 2006, p. 57.

9 Juan Carlos Henao Pérez, El daño. Análisis comparativo de la responsabilidad extracontractual del Estado en derecho colombiano y francés, Bogotá, Universidad Externado de Colombia, 2007, p. 84. 
De otra parte, la imputación a la que alude el artículo superior referido instituye dos subtipos: la imputación fáctica y la jurídica.

En el pasado, la primera de ellas fue comprendida como el nexo de causalidad y hoy se ha revalorado como imputación fáctica ${ }^{10}$ en procura de salvaguardar tanto las acciones como las omisiones del Estado, de manera que pueda mantenerse una adecuada fundamentación teórica y filosófica, pero que enmarca la posibilidad de atribuir el daño a las actuaciones y omisiones de una entidad pública. ${ }^{11}$

La segunda órbita de la imputación -la jurídica- es donde se encumbran las razones o los fundamentos por los cuales el Estado debe responder, es decir, "una razón jurídica suficiente por la cual las consecuencias económicas del daño deben ser asumidas por este y no por la víctima", ${ }^{12}$ denominados como títulos de imputación y que han tenido un profundo desarrollo por parte de la jurisprudencia. ${ }^{13}$

En la actualidad se reconocen, sin debate alguno en el derecho colombiano, la falla en el servicio, el daño especial y el riesgo excepcional, como títulos de imputación; el segundo de los cuales será explicado en las líneas que a continuación se esbozan por tratarse del tema central de este escrito: "Y, por último, que en Colombia [...], el fundamento de la responsabilidad extracontractual del Estado sigue siendo múltiple (falla del servicio, riesgo y ruptura de la igualdad frente a las cargas públicas)". ${ }^{14}$

Teniendo entonces un recuento de los elementos que actualmente se reconocen respecto a la responsabilidad del Estado en el derecho colombiano, el análisis se centrará en el daño especial como título de imputación, tanto en las disposiciones nacionales como en el derecho francés.

\section{El daño especial como título de imputación en la responsabilidad del Estado}

El daño especial se reconoce, entonces, como parte del régimen objetivo de responsabilidad del Estado, esto es, que prescinde plenamente del elemento

10 Enrique Gil Botero, “La teoría de la imputación objetiva en la responsabilidad extracontractual del Estado en Colombia", en Carlos Bernal Pulido y Jorge Luis Fabra Zamora (eds.), La filosofía de la responsabilidad civil. Estudios sobre los fundamentos filosófico-jurídicos de la responsabilidad civil extracontractual, Bogotá, Universidad Externado de Colombia, 2013, pp. 471-511.

11 Patiño Domínguez, "El trípode o el bípode: la estructura de la responsabilidad", op. cit.

12 Luis Felipe Botero Aristizábal, Responsabilidad Patrimonial del Legislador, Bogotá, Legis, 2007, p. 111.

13 Jaques Moureau, "El papel de la jurisdicción administrativa francesa en la creación (construcción) del derecho de la responsabilidad administrativa", en Alberto Montaña Plata y Andrés Eduardo Ospina Garzón (eds.), 100 años de la jurisdicción de lo contencioso administrativo: justificación, retos y aporte al Derecho administrativo, Bogotá, Universidad Externado de Colombia, 2014, pp. 225-242.

14 Felipe Navia Arroyo, “La responsabilidad extracontractual del Estado a la luz del artículo 90 de la Constitución Política", Revista de Derecho Privado 6 (2000), p. 231. 
culpa o dolo. Así, ha sido usado por la jurisprudencia para atribuir responsabilidad al Estado en los casos en los que se ha producido un actuar legítimo, que ha desequilibrado las cargas públicas que deben soportar los ciudadanos $\mathrm{y}$, por tanto, ha dado al traste con el principio de igualdad, lo que ha generado un daño anormal y grave al administrado.

Dicho fundamento de responsabilidad inició su consagración en el fallo Couitéas de $1923,{ }^{15}$ en el cual se determinó lo siguiente:

... aunque el gobierno tiene el deber de valorar las condiciones de la ejecución y el derecho a denegar el auxilio de las fuerzas armadas, si considera que puede poner en peligro el orden y la seguridad, el perjuicio resultante de esta denegación no puede, cuando supere una determinada duración, ser una carga que deba asumir el interesado en circunstancias normales. ${ }^{16}$

Como se dijo precedentemente, la consagración de dicho título de imputación obedeció a una necesidad de cambio en el derecho francés, en procura de superar casos en los cuales no se lograba la prueba de la falla en el servicio $\mathrm{e}$, incluso, se trataba de graves situaciones de injusticia que quedaban sin cobertura por parte del ordenamiento jurídico, tratándose entonces de un título de imputación de carácter excepcional, esto es, que solo podía ser aplicado en unos reducidos casos, para no desnaturalizar la responsabilidad del Estado:

... Hasta 1918 el Consejo de Estado francés venía aplicando las tesis de la falla o falta del servicio para resolver los contenciosos sobre responsabilidad estatal; sin embargo, las dificultades probatorias para establecer la falla del servicio, la idea de "riesgo creado" por la cercanía de un servicio público y el concepto de "lesión anormal", llevaron a este alto tribunal a abandonar en algunos casos los postulados de la falla del servicio y a establecer de esta manera un tipo de responsabilidad estatal de tipo objetivo. ${ }^{17}$

En aras de su adecuada limitación, se establecieron en el derecho francés unos elementos para poder configurar la aplicación del daño especial, así:

... la idea según la cual solo hay carga pública cuando el que reclama una compensación ha padecido una suerte más desfavorable que implican los inconvenientes normales de la vida social $[\ldots]$ la especialidad es una condición inherente a la responsabilidad por ruptura de la igualdad antes las cargas públicas. ${ }^{18}$

Conseil D'état Français', "Responsabilité pour rupture de l'égalité devant les charges publiques”, en https:// www.conseil-etat.fr/ressources/decisions-contentieuses/les-grandes-decisions-du-conseil-d-etat/conseil-detat-30-novembre-1923-couiteas, fecha de consulta: 10 de enero de 2020.

16 Marceau Long, Prosper Weil, Guy Braibant, Pierre Devolvé y Bruno Genevois, Las grandes sentencias de la jurisprudencia administrativa, Madrid, Editions Dalloz, 2019, p. 326.

17 William Guillermo Jiménez, "Origen y evolución sobre las Teorías de la responsabilidad Estatal”, Revista Diálogos de saberes 38 (2013), p. 74.

18 Michel Paillet, La responsabilidad administrativa, Bogotá, Universidad Externado de Colombia, 2001, p. 219. 
Ahora bien, al estar consagrado dicho título de imputación en el derecho comparado y ser receptor el derecho colombiano de las instituciones jurídicas allí encumbradas, se acogió el mismo, tanto en la doctrina como en la jurisprudencia.

En torno a ello, vale la pena señalar varias definiciones efectuadas en el derecho colombiano sobre este, antes de contextualizar su origen en el país latinoamericano:

El daño especial como fundamento de la responsabilidad se debe corresponder con los siguientes criterios: (1) cuando se produce el daño antijurídico este debe ser anormal (2) a partir de una actividad lícita del Estado; (3) que en el desarrollo de la misma se concrete una ruptura de la igualdad de las cargas públicas. ${ }^{19}$

El régimen de daño especial se configura [...] cuando existe una actuación lícita del Estado que, a pesar de ser desarrollada en interés público, esto es, en beneficio de la generalidad, causa un daño grave a una persona o a un grupo de personas que rompe la igualdad de los ciudadanos frente a las cargas públicas. ${ }^{20}$

A su vez, la jurisprudencia del Consejo de Estado ha definido el daño especial en los siguientes términos: “... en la cual el título de imputación tiene fundamento en la equidad y en la solidaridad como materialización del reequilibrio ante una ruptura de la igualdad frente a las cargas públicas, fruto del perjuicio especial y anormal que debe soportar el administrado". ${ }^{21}$

En tal medida, los requisitos que se reconocen hoy como imprescindibles para la aplicación del daño especial como título de imputación, retomados del derecho francés y el colombiano, una vez agotados los demás pasos del juicio de responsabilidad, son los siguientes, mismos que se establecen a partir de una interpretación propia que recoge los aspectos estatuidos por la jurisprudencia y la doctrina citadas:

- Un actuar legítimo y lícito del Estado: en este tópico se considera el daño especial como un título de imputación en el que se endilga al Estado un deber de reparación habiendo realizado una conducta amparada en el ordenamiento jurídico, es decir, no se realiza ningún reproche al actuar del Estado y, sin embargo, podrá generarse la consiguiente responsabilidad.

- Ruptura de las cargas públicas asignadas a los ciudadanos: el título de imputación estudiado se fundamenta esencialmente en el principio de igualdad contenido en el artículo 13 de la Carta Política de 1991. Bajo esos términos, al ser los ciudadanos iguales ante la ley, están obligados a soportar las mismas

19 Jaime Orlando Santofimio Gamboa, Compendio de derecho administrativo, Bogotá, Universidad Externado de Colombia, 2017, p. 775.

20 María Cecilia M'Causland, “Responsabilidad objetiva del Estado: tendencias, deseos y realidades”, en Juan Carlos Henao y Andrés Fernando Ospina Garzón (eds.), La responsabilidad extracontractual del Estado, op. cit., p. 186.

21 Consejo de Estado de Colombia, Sala de lo Contencioso-Administrativo, Sección Tercera, Sentencia de 03 de mayo de 2007. Radicado: 16.696, C. P. Enrique Gil Botero. 
cargas que el Estado les imponga. Empero, si se lesiona la igualdad en la distribución de estas y solo unos cuantos deben soportar lo que corresponde a todos, estos efectivamente habrán sufrido un daño que el Estado debe reparar.

- Un daño especial y anormal causado al ciudadano: el nombre del título de imputación al que se alude da cuenta del carácter especial y anormal del daño que debe sufrir el ciudadano en virtud del actuar legítimo del Estado, ya que al estar al amparo del ordenamiento jurídico, no cualquier lesión debe ser protegida, de allí que se exija una real y relevante vulneración de los derechos del ciudadano.

En este punto, y de manera sintética, se han establecido los elementos fundamentales y diferenciadores del daño especial como título de imputación, para lo cual debe resaltarse que para su configuración se requiere, ineludiblemente, de la presencia de los tres.

A continuación, se aludirá a su nacimiento jurisprudencial en Colombia y al consenso que existe en la doctrina y las decisiones judiciales en torno al Caso "El Siglo" de 1947 como la sentencia fundante en dicho aspecto.

\section{La doctrina. La jurisprudencia y el nacimiento del daño especial como título de imputación}

Atendiendo al derecho pretoriano que ha predominado en la materia, el nacimiento del daño especial en Colombia se predica en torno a la primera vez que el mismo fue empleado por la jurisprudencia del Consejo de Estado en la resolución de una situación particular, lo que se remonta al año 1947.

Ahora bien, en lo atinente a la afirmación primigenia contenida en este apartado, esto es, el nacimiento del daño especial como título de imputación en 1947, existe acuerdo en la doctrina autorizada dado que, al unísono, ha predicado:

Valga a este propósito traer a colación un importante fallo de 1947 en el cual el Consejo de Estado condenó por primera vez al Estado colombiano con base en la teoría del daño especial, ampliando notablemente los regímenes de responsabilidad hasta ese momento aplicados. ${ }^{22}$

En Colombia se habló por primera vez de daño especial, en materia de responsabilidad del Estado con la sentencia de 29 de julio de 1947, proferida por el Consejo de Estado, en la que resuelve la pretensión de reparación perseguida por el periódico El Siglo. ${ }^{23}$

22 Juan Carlos Henao Pérez, "La jurisdicción de lo contencioso administrativo: cien años creando derecho a partir de precedentes jurisprudenciales", en Montaña Plata y Ospina Garzón, 100 años de la jurisdicción de lo contencioso administrativo, op. cit., p. 255.

23 Rosana Lizcano Orozco, “Daño especial: reflexiones sobre su autonomía como uno de los fundamentos de la responsabilidad objetiva", Revista Dixi 14 (15) (2012), p. 70. 
El Consejo de Estado acogió, por primera vez, la teoría del daño especial en la sentencia del 29 de julio de 1947, por la cual se resolvió el proceso incoado por El Siglo S.A contra la Nación. ${ }^{24}$

Como puede verse en las citas precedentes, los autores conciben, sin discusión alguna, el nacimiento del título de imputación daño especial a partir de la providencia referida de 1947. Empero, debe decirse que, más allá de lo indicado, no se hace una precisión de cara a las particularidades que dieron lugar a dicha sentencia, ni al adecuado uso del título de imputación en el caso concreto.

Por su parte, propio es referir que la misma jurisprudencia, tanto del Consejo de Estado como de la Corte Constitucional colombiana, reconocen que el nacimiento de la figura tiene como antecedente el citado caso:

Más, el Consejo de Estado, desde 1947, había analizado extensamente la responsabi-
lidad del Estado, por hechos u operaciones administrativas, haciendo clara diferencia
entre las vías de hecho y la operación administrativa analizando profundamente la
responsabilidad sin falta u objetiva, frente al daño especial. ${ }^{25}$

El daño especial cuenta con una larga tradición en la jurisprudencia de esta Corporación, siendo utilizada por primera vez en $1947 .{ }^{26}$

El Consejo de Estado aplicó por primera vez el régimen de responsabilidad objetiva fundada en la noción de daño especial, en la sentencia del 29 de Julio de 1947. ${ }^{27}$

En lo que a continuación se expone, se delimitarán las particularidades del caso y, posteriormente, se estructurarán las razones por las cuales la providencia referida erró en condenar al Estado bajo el título de imputación daño especial, por cuanto lo que allí realmente se presentaba era una falla en el servicio, lo que implica que el uso de dicho fundamento por parte de la alta corporación no fue preciso $y$, en esa medida, no puede consagrarse como hito fundante en Colombia en la materia, amén de que no se edificó como una aplicación adecuada de la ruptura de la igualdad de las cargas públicas desarrollada en el derecho francés.

\section{Los supuestos de hecho y las consideraciones de la sentencia de 29 de julio de 1947: el caso "El Siglo"}

Atendiendo a que el objeto central del análisis corresponde a las particulares situaciones que dieron lugar a la expedición de la Sentencia de 29 de julio de

24 María Cecilia M'Causland, “Responsabilidad objetiva del Estado: tendencias, deseos y realidades”, op. cit., p. 185.

25 Consejo de Estado de Colombia, Sala de lo Contencioso-Administrativo, Sección Tercera, Sentencia de 28 de octubre de 1976. Radicado: 1.482, C. P. Jorge Valencia Arango.

26 Consejo de Estado de Colombia, Sala de lo Contencioso-Administrativo, Sección Tercera, Sentencia de 03 de mayo de 2007. Radicado: 16.696, C. P. Enrique Gil Botero.

Corte Constitucional de Colombia, Sentencia C-286 de 03 de mayo de 2017, M. P. Gloria Stella Ortiz Delgado. 
1947 por parte del honorable Consejo de Estado de Colombia, con ponencia de Gustavo A. Valbuena, se procurará efectuar una descripción detallada de sus aspectos más importantes, en aras de sustentar adecuadamente la postura que aquí se adscribe. Por supuesto, se obviarán aquellos aspectos de la providencia cuya relevancia no se desconoce, pero que no se presentan como diametrales para los fines académicos propuestos.

Mediante Resolución 882 de 10 de julio de 1944, proferida por el director general de la Policía Nacional de Colombia, en el marco de la turbación de orden público declarada con ocasión de la detención del presidente Alfonso López Pumarejo en la ciudad de Pasto, se estableció una vigilancia y control del Estado a las redacciones de los periódicos y revistas, en procura de no alterar aún más el orden público, con información o disputas sobre la situación presentada.

Tratando de materializar ello, se dispuso que funcionarios públicos permanecerían en las redacciones de los periódicos cumpliendo con tal labor, de manera que ningún diario podía ser publicado sin la censura previa, medida que empezó a regir a partir del 11 de julio de 1944.

En la lista de cuidadores o censores no se asignó ninguno de ellos al periódico El Siglo, de manera que desde el día 11 de julio de 1944 nadie pudo ejercer las labores habituales en la entidad, de allí que no se hubiese presentado la publicación del periódico hasta el 07 de agosto del mismo año, previo nombramiento de los censores correspondientes, situación que, según la parte demandante, generó perjuicios materiales que debían ser indemnizados y para cuya consecución presentó la acción prevista en el artículo $68^{28}$ de la Ley 167 de 1941, dado que consideró que la situación presentada correspondía a una vía de hecho.

Por la trascendencia del acto administrativo reseñado, base de la discusión que aquí se presenta, se expone su contenido literalmente:

Resolución número 882 de 1944 (Julio 10). El director general de la Policía Nacional, en desarrollo del Decreto 1632 de esta fecha, Resuelve: $1^{\circ}$ Comisiónase a los señores Jefe de la Oficina de Información y Control de Noticias, al abogado Jefe de la Asesoría Jurídica y al mayor Alvaro González, del Ejército Nacional, para que revisen todo el material impreso destinado a la publicidad en las redacciones de los periódicos de la ciudad.

$2^{\underline{0}}$ En esta labor obrarán de acuerdo con los funcionarios citados, los señores Comandantes Guillermo Nieto Gracia, Alfonso Escobar Calvo, Diógenes Osorio, Alberto

28 Artículo 68. También puede pedirse el restablecimiento del derecho cuando la causa de la violación es un hecho o una operación administrativa. En este caso no será necesario ejercitar la acción de nulidad, sino demandar directamente de la Administración las indemnizaciones o prestaciones correspondientes. 
Lara y Benicio Arce, quienes permanecerán en las redacciones de los periódicos en el siguiente orden:

En El Tiempo, el señor Comandante Guillermo Nieto Gracia.

En El Liberal, el señor Comandante Alfonso Escobar Calvo.

En el Diario Popular, el señor Comandante Diógenes Osorio.

En El Espectador, el señor Comandante Alberto Lara.

En La Razón, el señor Comandante Benicio Arce.

Los señores Comandantes nombrados someterán el material visado por ellos a la revisión de uno cualquiera de los tres funcionarios cita dos en el artículo $1^{\circ}$ de la presente Resolución.

$4^{\text {o }}$ Todos los diarios o revistas periódicas no mencionados aquí que dan sometidos a las mismas restricciones establecidas en los artículos anteriores.

$5^{\mathrm{o}}$ El personal necesario para el estricto cumplimiento de lo prescrito en el artículo anterior, será oportunamente designado por la Dirección de la Policía.

Comuníquese y cúmplase.

Dada en Bogotá, a 10 de julio de $1944 .{ }^{29}$ (énfasis agregado)

Tras el examen de unos aspectos de forma y competencia, ${ }^{30}$ el Consejo de Estado realizó un estudio del artículo 68 referido y la posibilidad que se presentaba a través de este de lograr la indemnización de perjuicios, aun en causas en donde no se trataba de nulidad alguna.

Además de ello, la alta corporación claramente determinó que en el asunto no se trató de una vía de hecho, sino de unas irregularidades presentadas en la operación administrativa que pretendió materializar la referida Resolución 882 de 10 de julio de 1944.

Por tratarse de un asunto relevante para el caso, determinó como necesario adaptar la doctrina del derecho comparado sobre el daño especial, aspecto que obedece -según lo argumenta la decisión- a la imposibilidad de encausar el caso en el título de imputación por falla en el servicio y enriquecimiento sin causa, por considerar que todas las actuaciones que se realizaron por parte de la administración estuvieron ajustadas a derecho, así:

$29 \quad$ La cita es extractada de la providencia del Consejo de Estado de 29 de julio de 1947.

30 Los mismos solamente fueron reseñados aquí de manera sucinta, en la medida que estos ya habían sido resueltos en providencia previa: Consejo de Estado de Colombia, Auto de 25 de abril de 1945, mediante el cual se revoca auto que inadmitió la demanda y dispone su admisión. 


\begin{abstract}
Ahora bien: al aplicar tales doctrinas jurídicas, expuestas, según se ha visto, con envidiable claridad por eminentes tratadistas, es evidente, desde luego, que en el caso de autos debe desecharse por improcedente la relativa al enriquecimiento, puesto que el Estado no derivó ningún aumento de patrimonio con la suspensión del diario El Siglo, ni mucho menos con detrimento de esta Empresa; y, en cambio, acogerse la del daño especial, en armonía con la de la responsabilidad sin falta. ${ }^{31}$
\end{abstract}

Finalmente, concluyó que en el asunto resultaba aplicable dicho título de imputación, así:

\begin{abstract}
En efecto: tanto por omisión como por acción, el periódico en referencia fue objeto de tratamiento excepcional. Lo primero, porque no se le nombró censor, a tiempo que a los demás órganos de la prensa diaria de Bogotá se les designó el suyo; y, lo segundo, porque fueron suspendidos los servicios de fuerza eléctrica y de teléfonos en el edificio donde funciona, y este rodeado de una escolta de la Policía Nacional, que impedía la entrada y salida de las personas, elementos sin los cuales y medida con la cual no podía actuar. Es cierto que esta última fue tomada, en primer término, para proteger la Empresa de una multitud amenazante, pero la prolongación de ese estado de cosas hasta después de la diligencia de inspección ocular extrajuicio, colocó al prenombrado diario en situación excepcional. ${ }^{32}$
\end{abstract}

Atendiendo a todo ello, se ordenó el pago de la indemnización correspondiente a perjuicios materiales al periódico El Siglo S.A a cargo de la nación.

Adicionalmente, debe agregarse que se produjo salvamento de voto por parte del consejero Jorge Lamus Girón, quien reiteró la postura atinente a la falta de competencia del Consejo de Estado para conocer del caso, así como, que no podía predicarse la responsabilidad del Estado, en la medida que las causas de la parálisis de publicaciones en el diario fueron las propias omisiones de sus empleados. Amén de lo expuesto, criticó la expansión a títulos de imputación en donde no se predica una falta de la administración.

\title{
5. Análisis del caso "El Siglo", de 1947, y la verdadera presencia de una falla en el servicio
}

De manera preliminar debe establecerse que ninguno de los supuestos en materia de responsabilidad puede encuadrarse en abstracto en un fundamento específico, por el contrario, deben analizarse todos y cada uno de los supuestos fácticos y su correspondencia con uno u otro título de imputación. Por supuesto, en la tesis que aquí se defiende, justamente se trata de materializar dicha postura, en la medida que lo único que se efectúa es un examen por-

31 Consejo de Estado de Colombia, Auto de 25 de abril de 1945.

32 Consejo de Estado de Colombia, Sentencia de 29 de julio de 1947, C. P. Gustavo A. Valbuena. 
menorizado de las situaciones presentadas en el caso reseñado, en procura de establecer si verdaderamente se encontraban reunidos los presupuestos de un daño especial.

En torno al razonamiento específico que debe llevarse a cabo en cada supuesto de responsabilidad, adecuado es referir la posición del profesor Jaime Orlando Santofimio quien alude:

Debe tenerse en cuenta que la Sección Tercera del Consejo de Estado unificó en el año 2012 la jurisprudencia [...] en el sentido de afirmar que no existe un modelo cerrado, monolítico y restringido de los denominados "títulos de imputación", sino que, todo juez contencioso administrativo tiene la posibilidad de examinar todos y cada uno de los fundamentos que han operado en el régimen de responsabilidad del Estado, y aplicar aquél que pueda encuadrarse con base en los hechos y pruebas de cada caso. ${ }^{33}$

Valga además resaltar que tal postura de aplicación general del título de imputación por falla en el servicio no solo es aplicada en el derecho colombiano, sino también en el derecho francés, circunstancia que permite hacer más sólido el planteamiento que aquí se pretende sustentar, en la medida de la equiparación de ambos ordenamientos jurídicos en este aspecto: "La responsabilidad por falla simple fue confirmada en su posición de régimen general de la responsabilidad administrativa". ${ }^{34}$

Ahora bien, primigeniamente parecería que la aplicación general de la falla del servicio sería un asunto de nula trascendencia, no obstante, nada más ajeno a la realidad en la medida que, en últimas, esta generalidad lo que pretende es atar a la administración a su responsabilidad en aras de evitar futuras producciones de daño, de manera que una absolutización o generalización de los títulos de imputación del régimen objetivo acabaría con tal trascendental propósito. A dicha conclusión han llegado autores colombianos y foráneos al determinar:

... si la regla general es la responsabilidad sin culpa (sin falla del servicio), [...] se produciría un relajamiento inaceptable en el funcionamiento de la administración pública. A este propósito son contundentes las siguientes palabras de Prosper Weil: "Aunque el concepto de responsabilidad de la administración por quebrantamiento de la igualdad ante las cargas públicas constituye sin duda alguna un progreso, hay que evitar que su extensión desconsiderada lo desvirtúe hasta el punto de llegar a significar que la administración haga lo que quiera, siempre que luego indemnice a las víctimas de su acción". ${ }^{35}$

33 Jaime Orlando Santofimio Gamboa, Compendio de derecho administrativo, op. cit., p. 749.

34 Didier Truchet, "La evolución reciente de la responsabilidad administrativa en el derecho francés", Henao y Ospina Garzón, La responsabilidad extracontractual del Estado, op. cit., p. 324.

35 George Vedel y Pierre Devolvé, Droit administratif, París, PUF, 1990, t. 1, p. 590,citados por Felipe Navia Arroyo, "La responsabilidad extracontractual del Estado a la luz del artículo 90 de la Constitución Política", Revista de Derecho Privado 6 (2000), p. 231. 
Una vez clarificado el aspecto anterior, es necesario esbozar previamente el alcance del título de imputación por falla en el servicio que, se itera, es el primero por aplicar en todos los casos y que evolucionó de la falta en el servicio a la noción que actualmente se concibe.

Como se reseñó brevemente en la introducción a este escrito, la falta en el servicio se erigió como el primer título de imputación en el marco de la responsabilidad del Estado, en el cual se pretendía realizar un reproche a la administración por sus actuaciones u omisiones y actuar culposo, así: "El concepto adecuado es considerar la responsabilidad por falta del servicio, como dentro de la responsabilidad subjetiva. Como señalan Mazzeaud y Tunc, la falta de servicio es considera como 'la culpa' del servicio". ${ }^{36}$

Tal comprensión de la falta en el servicio, en efecto, se presentó a su vez en la jurisprudencia del Consejo de Estado colombiano que estatuyó: “una falta o falla del servicio o de la Administración por omisión, retardo, irregularidad, ineficiencia o ausencia del servicio". ${ }^{37}$

No obstante ello, el alcance que actualmente se reconoce a la falla en el servicio alude al incumplimiento por parte del Estado de las obligaciones que este tiene a cargo, de manera que su actuar se reputa ilícito o contrario al ordenamiento jurídico, lo cual supera la noción de culpa del derecho privado. Este título de imputación corresponde al régimen subjetivo en materia de responsabilidad del Estado, de manera que lo que en estos casos se realiza es un reproche a la institucionalidad, dado que no satisfizo todos y cada uno de los deberes que le correspondían: "Progresivamente, con componentes del derecho comparado y elementos propios de nuestra realidad nacional se ha venido sustentando la noción de falla del servicio en la jurisprudencia colombiana, que hoy emana de una responsabilidad subjetiva y condena la falta de prevención en la prestación del servicio público". ${ }^{38}$

Hoy, y desde la superación de la responsabilidad indirecta del Estado y, por consiguiente, de la falta en el servicio, se erige contundentemente a la falla como "la violación de un contenido obligacional a cargo del Estado". ${ }^{39}$

\footnotetext{
$36 \quad$ Pedro Pierry Arrau, "Algunos aspectos de la responsabilidad extracontractual del Estado por falta de servicio", Revista de Derecho Público 59 (1996), p. 290.

37 Consejo de Estado de Colombia, Sala de lo Contencioso-Administrativo, Sección Tercera, Sentencia de 28 de octubre de 1976. Radicado: 5125, C. P. Jorge Valencia Arango.

38 Luisa Fernanda García López y Tatiana Oñate Acosta, “La falla del servicio en Colombia: una aproximación desde su origen en el derecho comparado", Manuel Alberto Restrepo Medina (ed.), Derecho administrativo: reflexiones contemporáneas, Bogotá, Universidad del Rosario, 2017, p. 560.

39 Juan Carlos Henao Pérez, "La noción de falla del servicio como violación de un contenido obligacional a cargo de una persona pública en el derecho colombiano y el derecho francés", en AA.VV., Estudios de Derecho Civil: obligaciones y contratos. Libro homenaje a Fernando Hinestrosa 40 Años de Rectoría 1963-2003, Bogotá, Universidad Externado de Colombia, 2003, p. 66; Consejo de Estado de Colombia, Sala de lo Contencioso Administrativo, Sección Tercera, Sentencia de 29 de enero de 2009. Radicado: 16576, C. P. Ramiro Saavedra Becerra.
} 
De conformidad con la información esbozada, sin lugar a dudas, debe reseñarse que lo presentado en el marco de la operación administrativa realizada entre julio y agosto de 1944, que impidió la realización de las actividades de publicación por parte del periódico El Siglo constituyó una falla en el servicio, en la medida que la nación violó las obligaciones que le fueron asignadas con ocasión de la turbación del orden público referenciado.

Para sustentar lo expuesto vale la pena auscultar algunas de las particularidades que presentó el acto administrativo cuya materialización afectó los intereses jurídicos de la parte demandante; para ello se retratan las obligaciones a cargo del Estado, de conformidad con lo allí dispuesto:

- La revisión del material de publicidad de las redacciones de los periódicos de la ciudad de Bogotá, por parte de tres funcionarios: el jefe de la Oficina de Información y Control de Noticias, el abogado jefe de la Asesoría Jurídica y el mayor Álvaro González, del Ejército Nacional.

- Permanencia, vigilancia, revisión y remisión de documentos de comandantes del ejército en diversos periódicos como El Tiempo, El Liberal, el Diario Popular, El Espectador y La Razón.

- Brindar las mismas condiciones de operación durante el estado de sitio a los demás periódicos y revistas no mencionados expresamente en la resolución.

- Designar los funcionarios competentes para garantizar las condiciones de operación de los demás periódicos y revistas no mencionados expresamente en la resolución.

En primer lugar, debe recordarse que el acto administrativo en mención nombró censores en varios de los periódicos de la ciudad sin incluir en ellos, de manera expresa, al periódico El Siglo, aspecto reprochable en la medida que no existía razón alguna para no asignar en esta declaración de la administración un censor a todos y cada uno de los informativos de la ciudad, situación que históricamente se ha asociado al color político de la publicación (conservadora) en contra de un régimen liberal como el que vivía la época en donde, por si fuera poco, tenía presencia el doctor Laureano Gómez ${ }^{40} \mathrm{y}$, justamente, las líneas periodísticas se habían convertido en las más claras manifestaciones de oposición:

La enemistad entre los dos caudillos no era nueva. Existía desde el primer gobierno de López, y Gómez la había expresado desde entonces a través de El Siglo. Según López, Laureano Gómez se abrogaba el privilegio de atentar contra la vida de los colombianos, de difamar a los presidentes liberales y de preconizar la gue-

40 El cual había declarado la oposición férrea al mandato de López Pumarejo en 1940. 
rra civil sin temor a sanción alguna. De nuevo, tras la segunda elección de López, aparecieron en El Siglo los lemas de "acción intrépida", "atentado personal" y "república invivible". ${ }^{41}$

Como se observa, puede reprocharse allí a la administración la limitación de la libertad de prensa en el momento coyuntural presentado, atendiendo a las discrepancias políticas existentes.

Por otro lado, el mayor actuar ilegítimo de la administración se presentó en punto de la no aplicación adecuada del artículo 4 del acto, porque allí quedaba perfectamente claro que todos aquellos diarios o revistas que no estuviesen incluidos expresamente, serían sometidos a las mismas particularidades enlistadas, esto es, se les nombraría un censor que revisaría las publicaciones antes de su emisión. De cara a ello, existía una obligación concreta en cabeza de la nación, de conformidad con la Resolución 882 de 10 de julio de 1944, misma que fue incumplida, pues solo hasta el 07 de agosto del mismo año se produjo tal nombramiento del censor que permitió el retorno de la publicación a la esfera nacional.

Así las cosas, en este asunto se evidencia que, mucho antes del estudio del daño especial, era propio hacer un análisis en clave de la falla en el servicio, fundamento que hasta ese momento había desarrollado a profundidad el Consejo de Estado colombiano y que, como se ha argumentado, resultaba plenamente aplicable.

Aún más, si se realiza una revisión exhaustiva de los elementos del daño especial retratados en el capítulo inicial, se concluiría que los supuestos de hecho descritos en el caso no superarían el primer elemento de dicho título de imputación, en la medida que no se trató de un actuar legítimo y legal del Estado, tal como se dijo, pues en el sub judice se constató una clara lesión del Estado de las obligaciones que le fueron instituidas en una norma jurídica, como lo era la Resolución 882 de 10 de julio de 1944, más concretamente, la atinente a brindar las mismas condiciones de operación durante el estado de sitio a los demás periódicos y revistas no mencionados expresamente, así como designar los funcionarios competentes para garantizar las condiciones su operación.

En similar sentido, y más allá de la discusión que se efectuó en torno al carácter de vía de hecho u operación administrativa desencadenado, en la literalidad de la sentencia, la alta corporación reconoce la omisión en la que se incurrió al no nombrar un censor para el periódico El Siglo, situación que demuestra que, debiendo materializar una actuación concreta, esta no fue llevada a cabo por parte de la administración, lo que representa algo que se ha profundizado

$41 \quad$ Adolfo León Atehortúa Cruz, "El cuartelazo de pasto", Revista Historia crítica 37 (2009), pp. 148-169, en https://www.redalyc.org/articulo.oa?id=81111524010 
en la doctrina, relativo a que la omisión administrativa conlleva, de suyo, la configuración de la falla en el servicio por parte del Estado, en la medida que revela el incumplimiento de las funciones y obligaciones de la entidad cuando debía desplegar una actuación.

De otra parte, debe destacarse que el honorable Consejo de Estado, si bien realizó una referencia teórica muy precisa del daño especial como título de imputación y sus implicaciones, el juicio de adecuación del caso concreto a dicho supuesto de responsabilidad fue precario, pues se limitó a la literalidad del párrafo expuesto en apartados anteriores, sin discutir en momento alguno la presencia de la falla en el servicio en este asunto.

Además de lo precedente, si no fuese suficiente para sustentar la tesis aducida, debe indicarse que el Consejo de Estado parece afincar la posibilidad de predicar el daño especial aquí, en lo que denomina la segunda situación presentada, esto es, la suspensión de los servicios públicos a la entidad y la imposibilidad de ingresar al edificio, ya que considera que estas medidas se llevaron a cabo en un actuar legítimo del Estado para proteger a la entidad de la amenaza existente.

Al respecto, debe indicarse que la posibilidad de aplicar este título de imputación resulta aparente, en la medida que la fuerza pública no actuó allí en un ejercicio legítimo, por el contrario, las diligencias llevadas a cabo carecían de fundamento, es decir, no tuvieron sustento en el estado de sitio decretado ni en la resolución objeto de estudio, dado que allí no se disponía ningún cierre de las sedes de los periódicos, sino una limitación o revisión previa antes de su publicación, asunto que hubiese podido materializarse perfectamente de no ser por la ausencia de nombramiento del censor y la extralimitación de la entidad en el marco de las situaciones particulares que se vivían en el país en ese momento, exceso en sus funciones que refleja, una vez más, la falla en el servicio.

Amén de ello, ya evidenciándose la situación de la falla en el servicio, y al ser esta debidamente acreditada, no debía el Consejo de Estado hacer elucubración alguna en procura de edificar otro título de imputación, porque tal como lo reconoce la jurisprudencia, es el régimen subjetivo el primero por analizar en materia de responsabilidad del Estado.

Desde una arista opuesta, debe estudiarse el último aspecto relevante en torno a la posibilidad de aplicación del daño especial, de cara a la desigualdad presentada entre el periódico El Siglo y los diarios a los cuales les fue nombrado un censor desde el mismo 10 de julio de 1944. 
En sustento de dicha postura debe destacarse, en primera instancia, que desde el acto administrativo mismo no se puede considerar que se lesionó el ordenamiento jurídico superior en desmedro de la igualdad, en la medida que, en el artículo 4 se refirió que todos y cada uno de los periódicos de la ciudad debían estar regidos por lo allí dispuesto, más allá de que no fueran nombrados. Así que, desde la concepción misma, la declaración de voluntad -al menos desde una visión preliminar-puede mostrar claramente cómo trató de materializarse la igualdad de los demás informativos de Bogotá.

En segundo lugar, se presenta la situación en torno a que la lesión de la igualdad que aquí se desarrolló se dio por la clara presencia de una falla en el servicio en una operación administrativa, porque la materialización de la declaración de voluntad de la administración no fue ejecutada de manera perfecta, misma que hubiese permitido que todos y cada uno de los diarios continuaran en circulación, aunque censurados.

Finalmente, debe destacarse que la sola lesión de la igualdad en una situación particular no conduce de manera automática a la aplicación del daño especial como título de imputación, en la medida que, se itera, doctrinaria y jurisprudencialmente, para predicar el mismo se debe estar en presencia de los tres elementos expuestos en acápites previos y no únicamente en la ruptura de la igualdad de las cargas asignadas puesto que, se recalca, este reflejará su presencia en donde la desigualdad corresponda a un actuar legítimo del Estado, pero ello no obsta para aplicar falla en el servicio en aquellos supuestos en donde la lesión de la igualdad provenga de un actuar ilegítimo de este, como lo serían en la actualidad, por ejemplo, los tratos discriminatorios que lleve a cabo una entidad pública en contra de una mujer o un homosexual por el solo hecho de serlo y que conduzcan a un daño a dichos sujetos. Como puede verse, allí también se trata de una lesión de la igualdad derivada de un actuar ilegítimo del Estado -controvertir una norma jurídica superior- $y$, sin embargo, ello no lleva al terreno del daño especial, sino al de la falla en el servicio.

Como corolario de lo reseñado, y en procura de soportar la tesis que se ha delimitado, destruida la posibilidad de aplicar el título de imputación de daño especial en las particulares situaciones del caso "El Siglo", el empleo de la falla en el servicio no corresponde a un capricho de la suscrita, sino a la preferencia del último título de imputación en los escenarios de responsabilidad.

Lo anterior por cuanto el mismo, al ser el primero en su conformación jurisprudencial y el régimen subjetivo en materia de responsabilidad del Estado, se ha considerado como la regla general en este escenario, de manera que el juez, en sus propios raciocinios y en aplicación del principio iura novit curia, ${ }^{42}$

42 En torno al principio iura novit curia puede consultarse a Victoria Bohórquez Hernández, El iura novit curia en la aplicación del derecho en la decisión judicial. Estudio desde el derecho fundamental al acceso a la justicia, Medellín, Universidad de Antioquia, 2013. 
debe hacer un análisis de los supuestos y, una vez agotadas la configuración del daño y la presencia de la imputación fáctica, deberá estudiar si en el mismo puede reputarse la imputación jurídica bajo la falla en el servicio o, de lo contrario, acudir al régimen objetivo de responsabilidad, cuyos sustentos son el daño especial y el riesgo excepcional. ${ }^{43}$

La postura antedicha podría ser aún más clara si se acoge la tesis expuesta por algunos, que reconoce que el daño especial no solo debe analizarse después de agotar la procedencia de la responsabilidad del Estado en falla en el servicio, sino que constituye el régimen último, de manera que puede acudirse a este cuando se agote el estudio de dicha falla y el riesgo excepcional:

Desde 1989, el Consejo de Estado sostiene que esta teoría se aplica de manera excepcional y por equidad precisamente porque es subsidiaria, de modo que ha de recurrirse a ella tan solo en los eventos en los que el caso concreto no logre un encasillamiento en los otros regímenes de responsabilidad y se aprecie por el sentenciador que esa atipicidad puede generar una vulneración injustificada del principio de equidad. ${ }^{44}$

Ahora bien, entendiendo todos y cada uno de los argumentos expuestos, no queda otra cosa que afirmar la desnaturalización que se llevó a cabo en el fa1lo "El Siglo" respecto a los presupuestos de la ruptura de la igualdad de las cargas públicas del derecho francés, lo que alteró los presupuestos básicos que se habían reconocido en el caso Couitéas y estableció el daño especial como un título de imputación de poco rigor teórico o dogmático en los escenarios de la responsabilidad del Estado.

\section{El origen del daño especial en Colombia se remonta a 1973}

De conformidad con todo lo que se ha reiterado, y atendiendo a las razones por las cuales se esgrime que el caso de "El Siglo" de 1947 no puede constituir el hito fundante del daño especial en Colombia, por la indebida aplicación del título de imputación allí presentado, resulta entonces trascendente efectuar un análisis jurisprudencial que permita contemplar cuál debe considerarse el verdadero origen de esta figura en Colombia como título de imputación, reconociendo para tal su origen jurisprudencial, pero en un caso que verdaderamente hubiese sido susceptible de aplicación, de manera que pudiesen adaptarse de manera óptima las reglas estructuradas en la jurisprudencia francesa.

$43 \quad \mathrm{Al}$ respecto pueden verse las consideraciones efectuadas en apartados precedentes sobre la generalidad de la falla en el servicio.

44 Rosan Lizcano Orozco, “Daño especial: reflexiones sobre su autonomía como uno de los fundamentos de la responsabilidad objetiva", Revista Dixi 14 (15) (2012), p. 77. 
Al respecto, vale la pena resaltar que del análisis de las decisiones judiciales proferidas por el Consejo de Estado colombiano a partir del 29 de julio 1947 y hasta el 22 mayo de $1973,{ }^{45}$ se encontraron ocho sentencias que hicieron mención al daño especial, empero, como se tratará a continuación, ninguna de estas puede erigirse como decisión hito en este caso, dado que no van más allá de una referencia tangencial al título de imputación, pero sin usar el mismo.

Al respecto, es prudente referir que seis ${ }^{46}$ de ellas aludieron de manera precaria al daño especial y a la ruptura de igualdad de las cargas públicas; sin embargo, los supuestos de hecho que se ocuparon de resolver correspondían a discusiones sobre trabajos públicos o expropiaciones administrativas, mismos que no correspondían a discusiones de responsabilidad extracontractual del Estado propiamente dichas.

Por su parte, vale la pena destacar la Sentencia de 22 de febrero de $1966,{ }^{47}$ en donde se hizo una escueta alusión al daño especial como título de imputación, sin embargo, no constituyó la ratio decidendi de la providencia, ya que allí se analizó una situación referida a las denominadas actividades peligrosas, por lo que no se reunieron los supuestos de hecho necesarios para el empleo del fundamento jurídico aquí estudiado.

Finalmente, dentro de dicho recuento jurisprudencial se encuentra la Sentencia de 30 de septiembre de $1949^{48}$ del Consejo de Estado colombiano, en donde si bien se realiza un análisis pormenorizado y profundo del daño especial -que de hecho terminaría siendo citado en providencia de 23 de mayo de 1973-, este no resulta aplicable, pues con anterioridad a acudir a la imputación jurídica se desestimaron las pretensiones de la demanda por ausencia de daño, de manera que tampoco pueden esgrimirse dichas consideraciones, a pesar de su claridad, como el origen jurisprudencial del daño especial en Colombia.

Es de cara a ello que debe esgrimirse como la sentencia clave en el reconocimiento de este fundamento la proferida por el honorable Consejo de Estado el 23 de mayo de 1973,49 en la medida que allí sí se hizo un correcto empleo del título de imputación, donde se cumplió con todos y cada uno de los aspectos determinantes de la teoría francesa y se dio una aplicación plena del mismo.

45 Gustavo Cuello Iriarte, El daño especial, como título de imputación de la responsabilidad del Estado -Historia. Legislación. Jurisprudencia, Bogotá, Instituto de Estudios del Ministerio Público IEMP, 2009.

46 Al respecto ver las siguientes providencias: Consejo de Estado de Colombia, Sentencia de 04 de septiembre de 1947, C. P. Carlos Rivadeneira; Sentencia de 04 de noviembre de 1949, C. P. Carlos Rivadeneira; Sentencia de 19 de abril de 1955. Radicado: E-5394, C. P. Rafael Rueda Briceño; Sentencia de 20 de marzo de 1956, C. P. Idelfonso Méndez; Sentencia de 02 de noviembre de 1960. Radicado: E-298, C. P. Carlos Gustavo Arrieta; Sentencia de 15 de octubre de 1960. Radicado: E-300, C. P. Gabriel Rojas Arbeláez.

15247 Consejo de Estado de Colombia, Sentencia de 22 de febrero de 1966, C. P. Jorge de Velasco Álvarez.

48 Consejo de Estado de Colombia, Sentencia de 30 de septiembre de 1949, C. P. Pedro Gómez Parra.

49 Consejo de Estado de Colombia, Sala de lo Contencioso-Administrativo, Sección Tercera, Sentencia de 23 de mayo de 1973. Radicado: 978, C. P. Alfonso Castilla Saiz. 
Para efectuar un breve retrato de la providencia debe resaltarse que se trató de una demanda instaurada por una ciudadana en virtud de la destrucción de su casa y los bienes muebles que allí se encontraban por parte del Ejército Nacional, cuando intentaba atrapar a un delincuente que ingresó en ella.

El primer análisis efectuado por parte del Consejo del Estado fue la posible ocurrencia de una falla en el servicio por parte del Ejército Nacional -en aplicación del régimen general de responsabilidad-; empero, no encontró su acreditación en el proceso, pese a la valoración probatoria llevada a cabo.

Es justamente ante dicho fracaso que procede al uso del daño especial, determinando que en el sub judice efectivamente se configuraron sus presupuestos, enmarcados en el actuar legítimo de la administración -la persecución y muerte de un delincuente-, la ruptura de las cargas públicas soportadas por la demandante -a quien se le destruyó su casa en beneficio de la comunidad- y un daño anormal y grave, como fue la pérdida total de su propiedad y los enseres que allí se encontraban, no un daño irrelevante para el ordenamiento jurídico. $\mathrm{Al}$ respecto, se hace referencia a los aspectos esenciales de dicha decisión:

\begin{abstract}
De otro lado, en nuestro derecho administrativo se reconoce el deber de indemnizar a las personas a quienes se ocasionen perjuicios con motivo de la realización de trabajos públicos. No pueden estas personas impedir la realización de dichos trabajos, y en esto cede su interés en favor del interés público; sin embargo, se les reconoce el derecho a ser indemnizados; derecho que no puede sino inspirarse en el mismo principio de la igualdad de los individuos ante las cargas públicas..$^{50}$
\end{abstract}

Sin realizar una extensa exposición teórica sobre la materia, puede evidenciarse que en la providencia referida sí se hizo una revisión adecuada en punto del daño especial como título de imputación aplicable a la responsabilidad del Estado, estatuyendo de manera clara todos y cada uno de los supuestos de este título de imputación, así:

- Un actuar legítimo y lícito del Estado: “... la acción armada ejercida para capturar a Efraín González en cumplimiento de una orden judicial expedida por funcionario competente no constituye falla del servicio y fue, por lo mismo, legítima". ${ }^{51}$

- Ruptura de las cargas públicas asignadas a los ciudadanos: “... razón por la cual al Estado corresponde indemnizar el perjuicio causado, lo que equivale a hacer una equitativa distribución de las cargas públicas".$^{52}$ 
- Un daño especial y anormal causado al ciudadano: “... pero ella causó un perjuicio económico a un tercero ajeno a esos hechos, consistente en la destrucción de una casa de propiedad de ese tercero". ${ }^{53}$

De todo lo previamente escrito debe concluirse que el primer antecedente jurisprudencial en el derecho colombiano del daño especial es la providencia de 23 de mayo de 1973, decisión en la cual puede comprenderse una correcta aplicación del postulado teórico expuesto en el derecho francés, al reunir la plenitud de sus elementos.

Ante ello, no puede dejarse pasar que no se trata solo de una discusión teórica, sino que encuentra como utilidad la revaloración del daño especial en aras de la precisión conceptual y, en últimas, en procura de extinguir, desde su origen, esa expansión injustificada del daño especial en Colombia, en situaciones donde realmente no tiene ninguna prosperidad, tratando de disfrazar la responsabilidad del Estado de principio de solidaridad y convirtiendo a la institucionalidad en un asegurador universal de los daños de sus ciudadanos. ${ }^{54}$ Amén de ello, procura por un responsable ejercicio en derecho comparado, de manera que se produzca una adecuada adaptación de los desarrollos que se emplean en otras latitudes y no un uso indiscriminado que termina afectando la solidez teórica de las exposiciones allí realizadas.

\section{Conclusiones}

De conformidad con todos y cada uno de los aspectos previamente representados y estudiados en este escrito, vale la pena destacar las siguientes conclusiones:

- La ruptura de las cargas públicas como parte del régimen objetivo de la responsabilidad del Estado fue reconocida por primera vez por el Consejo de Estado francés en el caso Couitéas, mediante el cual se establecieron unos sólidos y claros requisitos para la aplicación de dicho título de imputación.

- La doctrina y la jurisprudencia colombiana reconocen que el nacimiento del daño especial como título de imputación se remonta al año 1947, en el caso "El Siglo".

- El título de imputación aplicable en un supuesto de responsabilidad no debe fijarse de forma abstracta, sino que debe responder a un análisis de las particulares situaciones que rodean el caso y su correspondencia con los fundamentos teóricos y normativos que la falla en el servicio, el daño especial o el riesgo excepcional suponen.

54 Al respecto, veáse Julián Andrés Pimiento, "Responsabilidad o solidaridad. El fundamento del deber de reparar en el ámbito de la responsabilidad extracontractual del Estado", Revista de Derecho Público 36 (2016), en http://dx.doi.org/10.15425/redepub.36.2016.14 
- Atendiendo a las particularidades que se presentaron en el caso "El Siglo" se hizo un uso indebido del daño especial como título de imputación, por cuanto no se cumplieron los presupuestos para la aplicación de este, en los términos estatuidos por el derecho comparado, sino que se evidenció una clara ocurrencia de una falla en el servicio.

- La falla en el servicio es reconocida como el supuesto o régimen general de aplicación en materia de responsabilidad del Estado, de manera que en el caso "El Siglo" debía analizarse, en primer lugar, la correspondencia con este título de imputación, el cual se ajustaba plenamente y, en esa medida, no podía hacerse uso del daño especial como fundamento de reparación.

- El origen verdadero y adecuado del daño especial en el ordenamiento jurídico colombiano es la sentencia del Consejo de Estado de 23 de mayo de 1973, donde se realizó una exposición teórica en la materia y se cumplieron con todos y cada uno de los requisitos para predicar dicho título de imputación, siendo este el momento en el cual puede comprenderse una consonancia con la jurisprudencia francesa en este aspecto, al realizar una adecuada adaptación de los estándares expuestos en el derecho comparado.

- Afincar el nacimiento teórico en Colombia del daño especial en una jurisprudencia en donde no debió aplicarse el mismo, sino la falla en el servicio, resta solidez conceptual a dicho fundamento, de allí que considere deba reconstruirse, con el propósito de que, desde el origen de la figura, se planteen unos aspectos rigurosos para su aplicación, para que deje de ser un título de imputación ampliado por la jurisprudencia de manera injustificada, lo que ha permitido reparaciones en procura de la solidaridad y no de la verdadera atribución de responsabilidad al Estado.

\section{Referencias}

Asamblea Nacional Constituyente, Constitución Política de 1991, Gaceta Constitucional, 1991.

Atehortúa Cruz, Adolfo León, "El cuartelazo de pasto", Revista Historia crítica 37 (2009). DOI: https://doi.org/10.7440/histcrit37.2009.08

Bohórquez Hernández, Victoria, El iura novit curia en la aplicación del derecho en la decisión judicial. Estudio desde el derecho fundamental al acceso a la justicia, Medellín, Universidad de Antioquia, 2013.

Botero Aristizábal, Luis Felipe, Responsabilidad patrimonial del legislador Bogotá, Legis, 2007. 
Cuello Iriarte, Gustavo, El daño especial, como título de imputación de la responsabilidad del Estado. Historia. Legislación. Jurisprudencia, Bogotá, Instituto de Estudios del Ministerio Público IEMP, 2009.

Duez, Paul, La responsabilité de la puissance publique, Paris, Dalloz, 1938.

Echevarría Acuña, Mario Armando, "El pensamiento liberal y su influencia en la responsabilidad del Estado", Revista Cultural Unilibre 1 (2011), pp. 21-27.

García López, Luisa Fernanda y Oñate Acosta, Tatiana, “La falla del servicio en Colombia: una aproximación desde su origen en el derecho comparado", en Manuel Alberto Restrepo Medina (ed.), Derecho administrativo reflexiones contemporáneas, Bogotá, Universidad del Rosario, 2017, pp. 559-588. DOI: https://doi.org/10.2307/j.ctt21kk146.22

Gil Botero, Enrique, Temas de responsabilidad extracontractual del Estado, Bogotá, Comlibros, 2006.

Gil Botero, Enrique, “La teoría de la imputación objetiva en la responsabilidad extracontractual del Estado en Colombia", en Carlos Bernal Pulido y Jorge Luis Fabra Zamora (eds.), La filosofía de la responsabilidad civil. Estudios sobre los fundamentos filosófico-jurídicos de la responsabilidad civil extracontractual, Bogotá, Universidad Externado de Colombia, 2013, pp. 471-511.

Gil Botero, Enrique, Tesauro de Responsabilidad Extracontractual del Estado. Jurisprudencia 2012-2014, Bogotá, Temis, 2015.

Gil Botero, Enrique, Tratado de responsabilidad extracontractual del Estado, Bogotá, Tirant lo Blanch, 2020.

Henao Pérez, Juan Carlos, “La jurisdicción de lo contencioso administrativo: Cien años creando derecho a partir de precedentes jurisprudenciales", en Alberto Montaña Plata y Andrés Eduardo Ospina Garzón (eds.), 100 años de la jurisdicción de lo contencioso administrativo. Justificación, retos y aporte al Derecho Administrativo. XIV Jornadas de Derecho Administrativo, Bogotá, Universidad Externado de Colombia, 2014, pp. 244-269. DOI: https://doi. org/10.2307/j.ctv13vdh8t.12

Henao Pérez, Juan Carlos, "La noción de falla del servicio como violación de un contenido obligacional a cargo de una persona pública en el derecho colombiano y el derecho francés", en AA.VV, Estudios de Derecho Civil: obligaciones y contratos Libro homenaje a Fernando Hinestrosa 40 Años De Rectoría 1963-2003, Bogotá, Universidad Externado de Colombia, 2003, pp. 58-114.

Henao Pérez, Juan Carlos, El daño. Análisis comparativo de la responsabilidad extracontractual del Estado en derecho colombiano y francés, Bogotá, Universidad Externado de Colombia, 2007. 
Jiménez, William Guillermo, "Origen y evolución sobre las Teorías de la responsabilidad Estatal", Revista Diálogos de saberes 38 (2013), pp. 63-78. DOI: https://doi.org/10.18041/0124-0021/dialogos.38.2013.1832

Lizcano Orozco, Rosana, “Daño especial: reflexiones sobre su autonomía como uno de los fundamentos de la responsabilidad objetiva", Revista Dixi 14 (15) (2012), pp. 68-81.

Long, Marceau, Prosper Weil, Guy Braibant, Pierre Devolvé y Bruno Genevois, Las grandes sentencias de la jurisprudencia administrativa, Madrid, Editions Dalloz, 2019.

M'Causland, María Cecilia, “Responsabilidad objetiva del Estado: tendencias, deseos y realidades", en Juan Carlos Henao y Andrés Fernando Ospina Garzón (eds.), La responsabilidad extracontractual del Estado: ¿Qué? ¿Por qué? ¿Hasta dónde?, Bogotá, Universidad Externado de Colombia, 2015, pp. 181-233.

Moureau, Jaques, "El papel de la jurisdicción administrativa francesa en la creación (construcción) del derecho de la responsabilidad administrativa", en Alberto Montaña Plata y Andrés Eduardo Ospina Garzón, 100 años de la jurisdicción de lo contencioso administrativo: justificación, retos y aporte al Derecho administrativo, Bogotá, Universidad Externado de Colombia, 2014, pp. 225-242. https://doi.org/10.2307/j.ctv13vdh8t.11

Navia Arroyo, Felipe, "La responsabilidad extracontractual del Estado a la luz del artículo 90 de la Constitución Política", Revista de Derecho Privado 6 (2000), p. 211-231.

Paillet, Michel, La responsabilidad administrativa, Bogotá, Universidad Externado de Colombia, 2001.

Patiño Domínguez, Héctor Eduardo, "El trípode o el bípode: la estructura de la responsabilidad", editores Juan Carlos Henao y Andrés Fernando Ospina Garzón, La responsabilidad extracontractual del Estado: ¿Qué? ¿Por qué? ¿Hasta dónde?, Bogotá, Universidad Externado de Colombia, 2015, pp. 166-180.

Pierry Arrau, Pedro, "Algunos aspectos de la responsabilidad extracontractual del Estado por falta de servicio", Revista de Derecho Público 59 (1996), pp. 287-309.

Pimiento, Julián Andrés, "Responsabilidad o solidaridad. El fundamento del deber de reparar en el ámbito de la responsabilidad extracontractual del Estado", Revista de Derecho Público 36 (2016). DOI: https://doi.org/10.15425/ redepub.36.2016.14

Saavedra Becerra, Ramiro, De la responsabilidad patrimonial del Estado, Bogotá,

Temis, 2004. 
Saavedra Becerra, Ramiro, De la responsabilidad extracontractual de la Administración Pública, Bogotá, Grupo Editorial Ibáñez, 2011.

Santofimio Gamboa, Jaime Orlando, Compendio de derecho administrativo, Bogotá, Universidad Externado de Colombia, 2017, en https://doi.org/10.2307/j. ctv18mspcq

Serrano Escobar, Luis Guillermo y Claudia Patricia Tejada Ruiz, La responsabilidad patrimonial del Estado, Bogotá, Ediciones Doctrina y Ley, 2014.

Truchet, Didier, "La evolución reciente de la responsabilidad administrativa en el derecho francés", Juan Carlos Henao y Andrés Fernando Ospina Garzón (eds.), La responsabilidad extracontractual del Estado: ¿Qué? ¿Por qué? ¿Hasta dónde?, Bogotá, Universidad Externado de Colombia, 2015, pp. 317-332.

Vedel, George y Pierre Devolvé, Droit administratif, Paris, PUF, t. 1, 1990.

\section{Jurisprudencia}

Congreso de la República de Colombia, Ley 167 de 24 de diciembre 1941, Diario Oficial, Año LXXVII, núm. 24853, 7 de enero de 1942, p. 1.

Conseil D'état Français, "Responsabilité pour rupture del'égalité devant les charges publiques", en https://www.conseil-etat.fr/ressources/decisions-contentieuses/les-grandes-decisions-du-conseil-d-etat/conseil-d-etat-30-novembre1923-couiteas. Fecha de consulta: 10 de enero de 2020.

Consejo de Estado de Colombia, Auto de 25 de abril de 1945, C. P. Gonzalo Gaitán.

Consejo de Estado de Colombia, Sentencia de 29 de julio de 1947, C. P. Gustavo A. Valbuena.

Consejo de Estado de Colombia, Sentencia de 04 de septiembre de 1947, C. P. Carlos Rivadeneira.

Consejo de Estado de Colombia, Sentencia de 30 de septiembre de 1949, C. P. Pedro Gómez Parra.

Consejo de Estado de Colombia, Sentencia de 04 de noviembre de 1949, C. P. Carlos Rivadeneira.

Consejo de Estado de Colombia, Sentencia de 19 de abril de 1955. Radicado: E-5394, C. P. Rafael Rueda Briceño.

158 Consejo de Estado de Colombia, Sentencia de 20 de marzo de 1956, C. P. Idelfonso Méndez. 
Consejo de Estado de Colombia, Sentencia de 02 de noviembre de 1960. Radicado: E-298, C. P. Carlos Gustavo Arrieta.

Consejo de Estado de Colombia, Sentencia de 15 de octubre de 1960. Radicado: E-300, C. P. Gabriel Rojas Arbeláez.

Consejo de Estado de Colombia, Sentencia de 22 de febrero de 1966, C. P. Jorge de Velasco Álvarez.

Consejo de Estado de Colombia, Sala de lo Contencioso-Administrativo, Sección Tercera, Sentencia de 23 de mayo de 1973. Radicado: 978, C. P. Alfonso Castilla Saiz.

Consejo de Estado de Colombia, Sala de lo Contencioso-Administrativo, Sección Tercera, Sentencia de 28 de octubre de 1976. Radicado: 5125, C. P Jorge Valencia Arango.

Consejo de Estado de Colombia, Sala de lo Contencioso-Administrativo, Sección Tercera, Sentencia de 28 de octubre de 1976. Radicado: 1.482, C. P. Jorge Valencia Arango.

Consejo de Estado de Colombia, Sala de lo Contencioso-Administrativo, Sección Tercera. Sentencia de 03 de mayo de 2007. Radicado: 16.696, C. P. Enrique Gil Botero.

Consejo de Estado de Colombia, Sala de lo Contencioso-Administrativo, Sección Tercera, Sentencia de 29 de enero de 2009. Radicado: 16576, C. P. Ramiro Saavedra Becerra.

Corte Constitucional de Colombia, Sentencia C-333 de 01 de agosto de 1996, M. P. Alejandro Martínez Caballero.

Corte Constitucional de Colombia, Sentencia C-286 de 03 de mayo de 2017, M. P. Gloria Stella Ortiz Delgado. 